\title{
0 pós-dramático, ou seja, a abstracção
}

\section{Didier Plassard}

\begin{abstract}
Afirmar que esta ou aquela forma de arte deve ser indiscutivelmente superior ou inferior àquela outra significa emitir juizos antes de passar pela experiência. Toda a história da arte dá testemunho da futilidade das regras de preferência estabelecidas a priori e demonstra a impossibilidade de antecipar o resultado da experiência estética.
\end{abstract}

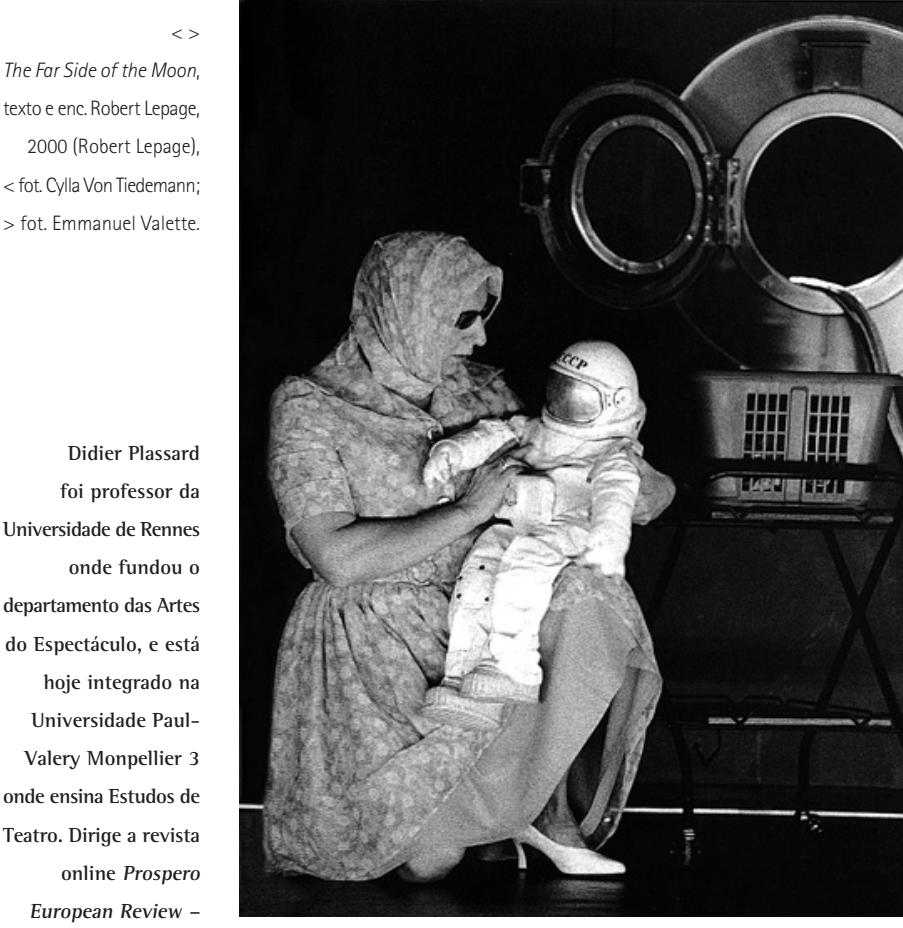

Research and Theatre

e é autor dos livros

L'acteur en effigie

(L'Âge d'homme, 1992,

Prix Georges-Jamati) e

Les mains de lumière (Institut International

de la Marionnette,

1996; rééd. 2005).

Dirigiu ainda a edição

dos livros Edward Gordon Craig, Drama for fools / Théâtre des

fous (L'Entretemps,

2012) et Mises en scène d'Allemagne(s)

de 1968 à nos jours (Les voies de la création

théâtrale, vol. 24, éditions du CNRS, 2012).
Algumas vantagens e desvantagens da noção de pós-dramático

Pelo facto de propor uma grelha analítica que permite pensar conjuntamente as experimentações que marcaram as últimas décadas do século $X X$, tanto no âmbito da escrita teatral como no das práticas cénicas, a noção de teatro pós-dramático, elaborada por Hans-Thies Lehmann apesar dos riscos da sua difusão internacional (erros e confusões na tradução, texto amputado de um terço, para citar apenas o caso da edição francesa), pôde rapidamente adquirir o estatuto de uma teorização geral da criação artística contemporânea, e até de uma nova doxa estética, suscitando as mais desencontradas tomadas de posição. Para além da sua notável força heurística, implantada em campos tão diferentes como o do tratamento da linguagem, do corpo, do espaço ou do tempo teatral, vários factores contribuíram para o seu êxito. Limitar-me-ei a citar dois deles: o primeiro, bem conhecido, é o de dar continuidade à Teoria do drama moderno, de Peter Szondi, que, em meados dos anos cinquenta, soube propor uma das sinteses

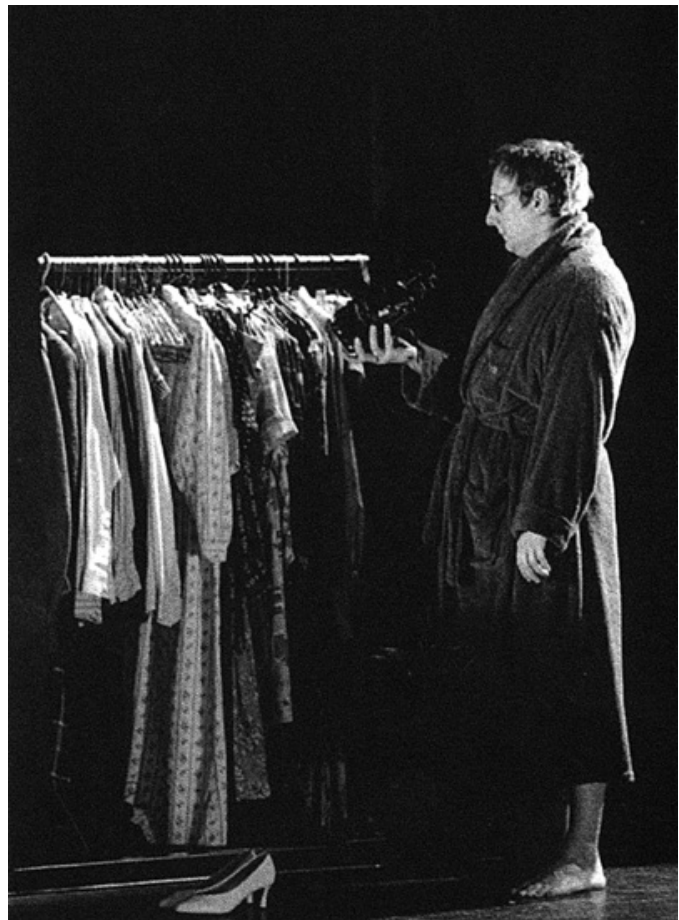

mais estimulantes da história do teatro europeu abarcando cerca de três séculos; o segundo factor, igualmente evidente mas cuja importância permanece subestimada, é a oportuna superação que a noção de teatro pós-dramático permitiu avançar relativamente aos fracos resultados da aplicação das teorias do pós-modernismo neste campo.

Diferentemente destas últimas, que se definem por uma oposição falsa e estéril relativamente aos modernistas da primeira metade do século XX a ideia de um teatro pósdramático dá a ler as mudanças surgidas depois do fim dos anos 60 na herança directa ou indirecta das vanguardas históricas, reatando assim os fios duma historiografia mais vasta e coerente. Aliás, a superação efectuada por Lehmann explica-se facilmente: as caracteristicas estilísticas consideradas como sendo pós-modernas (ecletismo, ironia deshierarquização, citação, etc.) vinham em linha directa do urbanismo e da arquitectura, e a oposição que era possivel estabelecer entre as realizações de um Rem Koolhaas ou de um Ricardo Bofill, dum lado, e as de um Adolf Loos ou de um Le Corbusier, do outro, tinha 
dificuldade em encontrar o seu equivalente no teatro, na literatura ou nas artes plásticas. Pode imaginar-se melhor realização desta estética "pós-modernista", de facto, do que o Ulisses de Joyce, os Cantos de Pound, a obra de Picasso ou o movimento Dada no seu conjunto? Ou então, no âmbito do teatro, a cena Merz de um Kurt Schwitters, as landscape plays (peças-paisagem) duma Gertrude Stein, as peças de Ribemont-Dessaignes e do primeiro Vitrac, o Teatro da Surpresa dos futuristas italianos, as encenações do grupo de realizadores e encenadores do FEKS (Fábrica do Actor Excêntrico) em Sampetersburgo ${ }^{1}$ ? Pelo facto de o momento modernista não ter seguido na arquitectura os mesmos caminhos que o das outras artes, a ideia de uma literatura, de uma pintura ou de um teatro pósmodernos não era pura e simplesmente pensável - a não ser, bem entendido, pela recusa em articular o modernismo com o pós-modernismo, o que não ajudava muito à sua compreensão ${ }^{2}$.

No entanto, mesmo que a ferramenta conceptual forjada por Hans-Thies Lehmann, ao oferecer uma visão mais ampla, surja como uma forma de sintese e de superação eficaz dos instrumentos críticos com cujo auxilio se escrevia até então a história do teatro do século $X X_{1}$ a meu ver não consegue dar totalmente conta da diversidade das mudanças ocorridas desde finais dos anos 60 nas artes do espectáculo, mudanças que, aliás, ainda hoje se processam.

Não irei associar-me, contudo, às diferentes refutações que puderam ser feitas de 0 teatro pós-dramático, baseadas, por exemplo - inclusive em França - em disputas de interpretação relacionadas com os respectivos papéis do autor e do encenador na emergência e desenvolvimento das novas estéticas teatrais ${ }^{3}$, mas defenderia antes a recuperação do essencial das análises contidas nesta obra no âmbito de um quadro conceptual ligeiramente diferente. Uma primeira reserva que pode ser levantada às teses defendidas por Lehmann é que a representação teatral, enquanto obra colectiva apresentada perante uma colectividade reunida, inscreve-se numa economia pesada e complexa, muitas vezes fortemente institucionalizada, que obriga a ter em conta diferentes expectativas: as dos espectadores, as dos financiadores públicos ou privados, as dos estabelecimentos que a produzem ou divulgam, etc. Por isso, a história das suas mudanças estéticas não é de forma alguma o produto duma evolução interna às artes do espectáculo, num processo contínuo de radicalização das etapas mais experimentais, como dá a crer 0 teatro pós-dramático, que sobrestima todas as formas de desvio, sendo a produção teatral remanescente empurrada para a sombra ou para a insignificância. Daí resulta que alguns dos maiores fazedores do teatro dos anos 1970-2000 são simplesmente omitidos ou silenciados, como é o caso de Giorgio Strehler, Dario Fo, Matthias Langhoff, Antoine Vitez, Patrice Chéreau, Krystian Lupa, Piotr Fomenko, Lev Dodine. E entre os autores, o mesmo acontece, por exemplo, com Thomas Bernhard, BernardMarie Koltès ou Edward Bond ${ }^{4}$. Esta história é também, e desde já, a das funções que a sociedade atribui à criação teatral, e que condicionam fortemente as condições de produção: obrigação do divertimento aqui, missão cultural e educativa acolá, para citar apenas as mais evidentes. Dai resulta que o desenvolvimento de formas inovadoras não se faça segundo um eixo único, uma linha de fuga traçada num espaço vazio, mas antes numa tensão dialéctica em relação aos hábitos adquiridos, às condições de produção e aos horizontes de expectativa instituídos, entre submissão, transformação e subversão, o que conduz a uma enorme diferenciação dos fenómenos observáveis.

Neste sentido, por exemplo, o movimento do In-yerface-theatre na Grã-Bretanha, o peso importantíssimo que em França assumiu, depois dos anos 80, a exploração do repertório clássico, o número considerável, um pouco por toda a Europa, das reescritas de tragédias ou de mitos gregos, o desenvolvimento de encenações inspiradas em cenários de filmes, tudo isto participou na renovação da arte do teatro, sem que estes fenómenos se possam reduzir aos modelos pós-dramáticos descritos por Lehmann: todos eles, pelo contrário, manifestam a conservação do dramático no centro da criação teatral contemporânea - um fenómeno que não creio que possa ser rapidamente varrido, como o faz o teórico alemão, rotulando-o de forma simplista como "teatro tradicional".

\section{Uma historiografia linear}

Para ser mais claro, o problema central que coloca o ensaio de Hans-Thies Lehmann reside, a meu ver, na conservação de uma historiografia linear, onde uma única forma de "novo" (o pós-dramático) viria substituir uma única forma do antigo ${ }^{5}$ (o dramático). Duas grandes dificuldades resultam deste esquema binário.

A primeira é a assimetria dos corpora observados. É fácil concordar, com Szondi, que o teatro ocidental tem sido amplamente dominado ao longo de dois séculos pela procura de uma forma puramente dramática, excluindo tanto quanto possivel os modos narrativo e lírico. Mesmo sendo necessário precisar que esta análise vale apenas para a parte mais institucionalizada da criação teatral, sob a sua forma ao mesmo tempo literária e séria - nem o vaudeville, a féerie, o monólogo, o repertório dos teatros de marionetas ou de outras formas de espectáculo populares se vergam a essa exigência -, a verdade é que, mesmo de um ponto de vista quantitativo, a procura de
'Um dos realizadores deste grupo que mais se destacou foi Grigori Mijailovich Kosintsev a que se juntou ainda Eisenstein.

${ }^{2} \dot{E}$ este aspecto em especial que fragiliza a estranha tentativa feita por Christophe Bident (2009 : 76-82) de devolver vigor ao "pósmodernismo" para substituir o "pósdramático".

${ }^{3}$ Vejam-se sobretudo os textos reunidos por Jean Pierre Sarrazac em 2007.

${ }^{4}$ A lista baseia-se no indice remissivo dos nomes próprios da edição original. Foram entretanto acrescentados nomes nas várias traduções, como em França, os de Duras e Koltès. 0 desequilibrio das escolhas de Lehmann emerge de modo ainda mais evidente se se proceder ao levantamento da lista dos artistas citados mais de 10 vezes na sua obra: são eles Artaud (12), Beckett (11) Brecht (36), Brook (13), Jan Fabre (24), Grüber (11), Handke (13), Lauwers (11), Mallarmé (14), Müller (39), Schleef (17), Wilson (40)

${ }^{5}$ A este respeito veja-se 0 artigo de Pierre Frantz 2005: 584-595. 
Elsinor

a partir de Hamlet, de William Shakespeare, texto e enc. Robert Lepage,

Montreal1995/

Nottingham Playhouse 1996 (Robert Lepage) fot. Donald Cooper.

um "drama puro", enxertada nas releituras de Aristóteles, define bem o movimento maioritário das cenas europeias entre cerca de 1660 e 1880.

Parece-me mais dificil admitir, por outro lado, que a crise do drama moderno analisada por Szondi se inscreva na mesma concepção da história do teatro: para o período que abrange o fim do século XIX e a segunda metade do $X X$, de facto, algumas considerações ligadas ao prestígio simbólico dum pequeno grupo de autores começam a misturar-se ao que, para os séculos anteriores, podia ser estabelecido a partir de uma simples base quantitativa: basta, por exemplo, consultar a lista de espectáculos representados numa grande capital europeia, entre as duas guerras mundiais, para se perceber que a forma dramática se porta ainda insolentemente bem. Por auto-ficção -, não estão afinal longe das direcções

abertas pela crise do drama - o teatro épico de

Piscator e Brecht - ou pelo teatro pós-dramático

(Heiner Müller). conseguinte, a história dos modos de representação dominantes encontra-se progressivamente substituída, na reflexão de Szondi, por uma história construida num corpus prestigiado, mas minoritário: o dos grandes autores do repertório moderno.

Este deslizar é ainda mais acentuado em Lehmann, apesar de a sua famosa estratégia retórica do namedropping (de ir atirando com extensas listas de nomes mais ou menos conhecidos) ter a função de o ocultar, e de fazer passar por uma só corrente unitária de grande amplitude opções artísticas que se cristalizaram em lugares de produção ou de difusão muitas vezes atípicas (Mickery Theater, Kaaitheater, Theater am Turm, etc.) ou de festivais, ou seja nos espaços mais abertos à experimentação no âmbito da paisagem ela própria protegida do teatro público. Antes de examinar a hipótese, avançada por Lehmann, duma mudança de paradigma estético, é portanto necessário tomar nota da mudança do paradigma historiográfico que pratica, quando opõe ao teatro "tradicional", logo, maioritário, um "novo" teatro construído como a soma das etapas mais radicais, efectuadas perante um público bastante restrito. As análises de Pierre Bourdieu, distinguindo - em Les règles de l'art (1992) - o campo das obras com forte capital económico e fraco capital simbólico, do que se refere às obras com forte capital simbólico e fraco capital económico, deveriam aqui ser tidas em conta, mesmo que seja preciso matizá-las, obviamente devido a condições mais favoráveis à experimentação que oferece (seria mais exacto dizer "que oferecia") ao espectáculo ao vivo, expecialmente na Alemanha e em França, o financiamento público da criação.

Aos problemas metodológicos colocados por este deslizar de um paradigma historiográfico para outro dado que as "dominações" exercidas pelo modelo dramático anterior e pelo modelo pós-dramático actual não são nem da mesma amplitude nem da mesma natureza - vêm
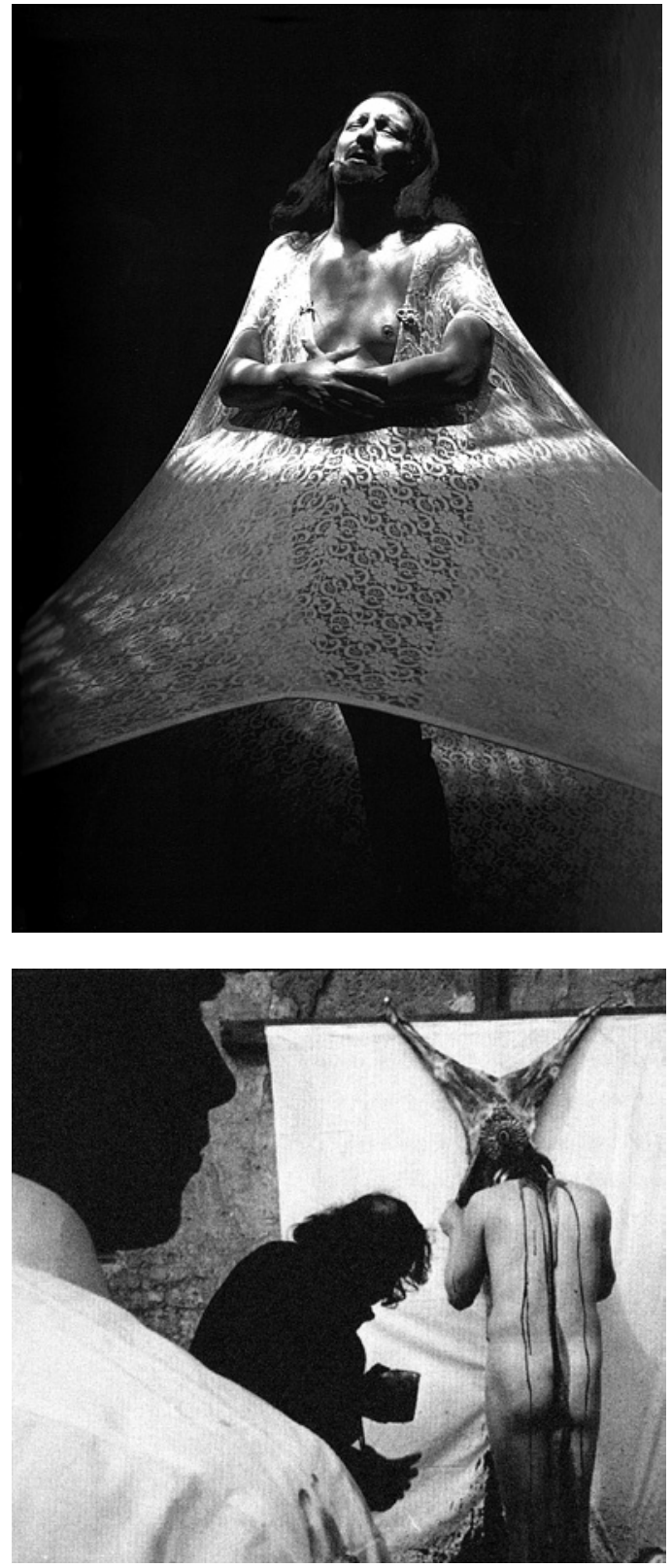

acrescentar-se a outras dificuldades vindas do que em bom rigor se deve chamar uma concepção muito "moderna" (hegeliana, de facto) da História, como série de superações sucessivas orientadas para um progresso contínuo. Segundo este esquema, tudo o que antecede a pesquisa de um drama puro, desde a tragédia grega ao teatro da época barroca, é de algum modo pré-dramático; segue-se o teatro dramático, que exerce o seu domínio desde meados do século XVII até finais do XIX, depois a crise do drama correspondente aos dois primeiros terços do século $X X$, finalmente o teatro pós-dramático a seguir ao qual toda e qualquer recuperação da forma dramática parece tão improvável - ou pelo menos tão estranha ao seu tempo - como seria o reestabelecimento da monarquia absoluta numa sociedade democrática. 0 livro editado por HansThies Lehmann não opõe apenas, num passado recente, a emergência de um "novo teatro" aos restos de um teatro desqualificado como "tradicional": ele bloqueia ainda o futuro definindo toda a forma de regresso do dramático como um retrocesso ${ }^{6}$. 

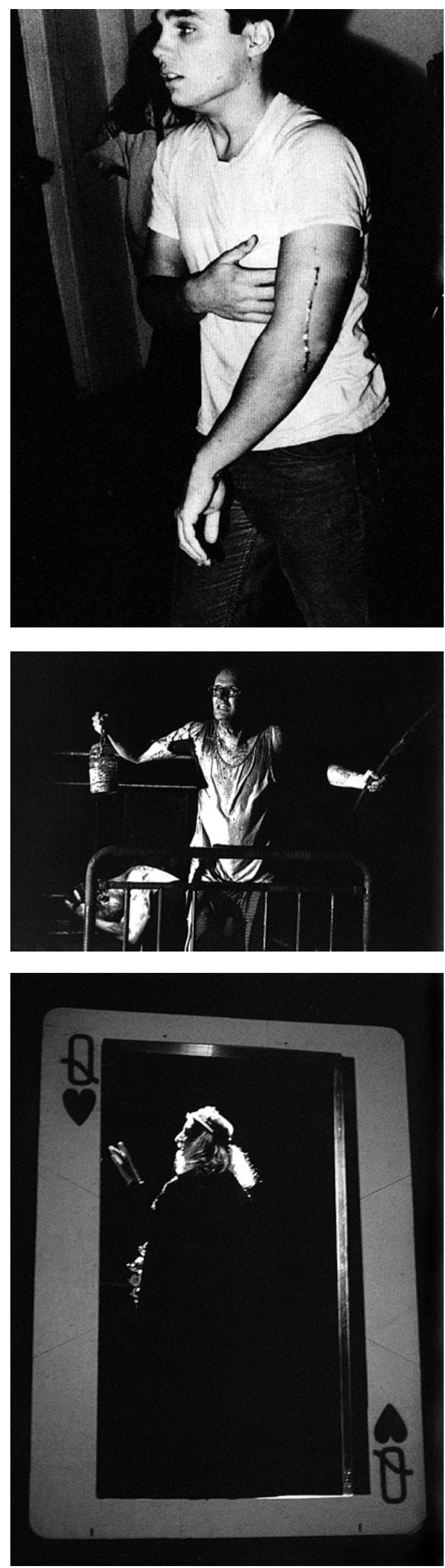

Shoot

de Chris Burden,

New York, 1971

(Chris Burden), fot. Alfred Lutjeans, ${ }^{\odot}$ Chris Burden.

Esta concepção linear e vectorial da História, como uma "flecha do tempo" portadora de um desenvolvimento contínuo, há muito perdeu a sua função de modelo explicativo das mudanças políticas e sociais: a crença no progresso da razão, o desaparecimento dos conflitos, a realização duma sociedade sem classes está em vias de desaparecimento com o colapso do bloco comunista, e o seu último avatar, o fim da História teorizada por Francis Fukuyama (1992), quase caiu no esquecimento. Postular que o teatro dramático encontraria a sua superação no teatro pós-dramático, tal como o faz Lehmann, conduz a manter a organização vectorial do tempo - e ainda o mito do progresso - como esquema explicativo para escrever a história desta arte, o que coloca o problema de interpretar as dinâmicas próprias do campo artístico segundo os modelos considerados como obsoletos noutros campos: é mesmo, paradoxalmente, continuar a pensar em termos "modernos" a emergência de obras consideradas como "pós-modernas".

Um teatro abstracto?

A meu ver, portanto, convém recuperar a análise proposta por Lehmann das formas teatrais pós-dramáticas na superação do esquema historiográfico linear em que se fecha. 0 pós-dramático não é uma superação hegeliana do teatro dramático, que acompanha uma Aufhebung sem possibilidade de regresso: é apenas uma direcção tomada por algumas correntes contemporâneas das artes do espectáculo que, de certo modo, convergem entre si e que ocupam temporariamente, sobretudo na Alemanha, uma verdadeira posição de domínio institucional, correndo deste modo o risco de formar um novo academismo, como aliás denuncia Bernd Stegermann (2008). Mas a arte é um processo de transformação contínuo, e os academismos são sempre possiveis de serem ultrapassados, derrubados, refundidos para que se abram novas direcções.

Queria agora tentar, num esboço rápido, identificar melhor o que me parece caracterizar esta orientação "pósdramática" adoptada por um certo número de produções cénicas contemporâneas. A minha hipótese é que as mudanças descritas por Hans-Thies Lehmann realizam, no âmbito da criação teatral, uma forma de passagem à abstracção comparável à que atravessou as artes plásticas nos anos 1900-1930, com o abandono da figuração.

Entendo aqui o termo "abstração" no sentido mais simples, tal como se impôs na história da arte: o de uma ausência de relação mimética entre a obra apresentada e o mundo em que vivemos. Esta ausência - é preciso lembrá-lo - é muitas vezes aparente do ponto de vista da concepção da obra, porque a relação mimética, Aristóteles notava-o já em relação à música (Política, livro VIII, cap.
A Midsummer Night's

Dream,

de William Shakespeare, enc. Robert Lepage, Royal National Theatre, 1992, fot. Neil Libbert.

Elsinor

a partir de Hamlet

de William Shakespeare, texto e enc. Robert Lepage Montreal1995/

Nottingham Playhouse 1996 (Robert Lepage) fot. Richard Max Tremblay. 


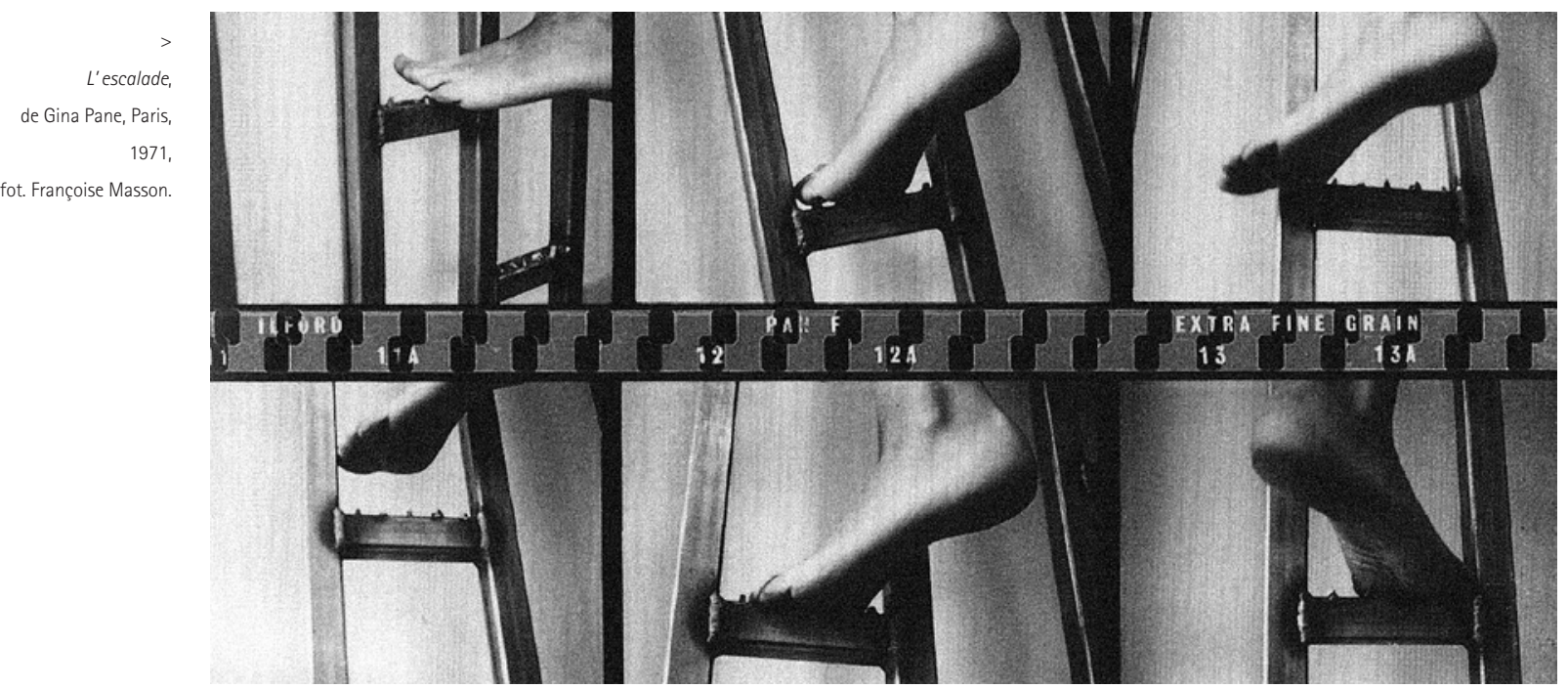

5), pode estabelecer-se fora de qualquer figuração exterior entre as estruturas internas da composição e as emoções humanas. Do ponto de vista da sua recepção, pode ocorrer o mesmo, na medida em que o movimento da interpretação é infinito, uma vez que mobiliza as forças da imaginação, da memória individual e a herança cultural para nos fazer descobrir em cada objecto uma possivel dimensão icónica (Gombrich 1986: 15-32). É deste modo que Michael Fried, no seu célebre ensaio Art and objecthood, de 1967, pode culpar Robert Morris e Tony Smith de conservarem uma forma de antropomorfismo e até de teatralidade nas suas esculturas minimalistas, através do jogo das proporções ou das posições de simples blocos em paralelepípedos ( $\mathrm{v}$. Didi-Huberman 1992: 85-102).

Para a história do teatro, as premissas desta passagem à abstração são as pesquisas das primeiras décadas do século XX. Recordemos que um grande número de artistas pintores que fundaram a arte astracta reflectiram sobre os seus possiveis prolongamentos em cena: é o caso de Kandinsky, com as suas Composições cénicas antes da Primeira Guerra Mundial ou a sua encenação dos Quadros de uma exposição de Moussorgski em 1928; de Malevitch que realizou cenários e figurinos para a ópera futurista $A$ victoria sobre o sol de Kroutchonykh e Khlebnikov em 1913; ou ainda de Mondrian, que reflectiu sobre as possibilidades de um espectáculo de projecções néoplasticistas, no começo dos anos 20, e a seguir a uma encenação de 0 efémero é eterno de Michel Seuphor sem a presença de nenhum actor vivo. É o caso ainda de muitos outros, como os pintores futuristas italianos, os companheiros do Dada, os mestres e alunos da Bauhaus os construtivistas e formalistas. Logo após a Segunda Guerra Mundial, inicia-se uma segunda fase de exploração de possibilidades de um teatro abstracto, em espaços onde a experimentação cénica e a exploração dramatúrgica se desenvolvem inicialmente de maneira separada (eventos, happening e performance nos Estados Unidos, teatro chamado "do absurdo" em França, etc.), mas voltam a cruzar-se desde finais dos anos 50 num Jacques Poliéri, por exemplo. 0 teatro pós-dramático dos anos 70 e seguintes inscreve-se directamente no prolongamento destas experiências levando-as a um nivel superior de concepção e de elaboração, de circulação internacional e de visibilidade institucional, mas sem que as orientações profundas da pesquisa artística sejam verdadeiramente modificadas. Também as vanguardas históricas e as neovanguardas pós-1945 não constituiram uma "pré-história" do teatro pós-dramático - como sugere Hans-Thies Lehmann, que aliás não as evoca senão muito vagamente (somente o nome de Schwitters é mencionado entre dois parêntesis) - mas antes o momento da sua aparição, facto estabelecido há muito pelos trabalhos de RoseLee Godberg sobre a performance art.

0 processo desencadeado por este teatro pósdramático, que Lehmann descreve como formas de autoreflexão, de decomposição, de separação (Lehmann 1999 77 | 2002: 69) ou de desaparecimento dos componentes da cena "tradicional", segundo a lógica da Aufhebung hegeliana, pode a meu ver reportar-se a operações de dissociação ${ }^{7}$ de certos funcionamentos simbólicos, sem excluir no entanto a possibilidade de estes reaparecerem sob a forma de novos agenciamentos. Uma das mais óbvias é, muito claramente, a "dissociação da narratividade": os elementos e os acontecimentos textuais ou cénicos já não são agenciados em função duma fábula, tal como ocorria no teatro pré-classico, composta pelo entrecruzar-se de histórias múltiplas. Não é apenas o desenvolvimento completo de uma acção (exposição, crise e desfecho) que foi abandonado pela escrita teatral ou desconstruido pela encenação: é o seu próprio encadeamento, ou seja a possibilidade dada ao espectador de voltar a associar, pela lógica ou pela imaginação, as múltiplas informações que recebe.

Portanto, se a esmagadora maioria das dramaturgias contemporâneas abandona as perícias artesanais da construção do enredo, marcando assim uma distância em relação ao cinema comercial ou às telenovelas, isso não implica necessariamente que elas tenham perdido toda a dimensão narrativa, como muitas vezes se julga. No caso de haver dissociação, ela diz respeito principalmente à macroestrutura do texto ou da representação, enquanto a nivel microestrutural historietas, histórias de vidas, curiosidades, acontecimentos históricos, mitemas e outros topoï narrativos continuam a ser mobilizados. Da mesma forma, a diminuição do espaço do texto na economia da representação teatral não inviabiliza, como por vezes se afirma, a capacidade de contar: a integração em cena do vídeo, das redes de comunicação, da dança ou da 

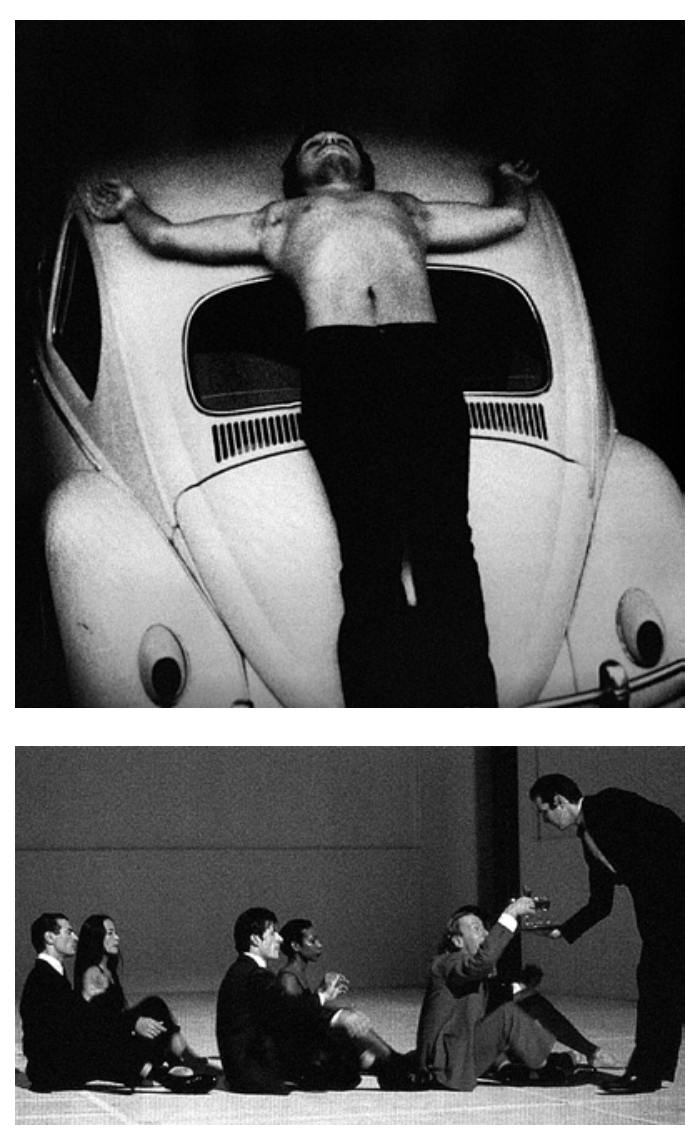

performance desloca e reconfigura as modalidades da narração, mas não as faz desaparecer. A "dissociação da narratividade" designa então um processo de transformação através do qual a variedade das acções cénicas deixa de se fundir numa totalidade organizada, conduzida principalmente através da linguagem. Este processo, por outro lado, é desde há muito tão utilizado que tende a a ser substituído, depois de cerca de vinte anos, por novos modos de construção dramatúrgica, mais complexos e diversificados ao mesmo tempo: o teatro no Québéc (de Lepage, Danis, Mouawad), na Bélgica (do Groupov, Cassiers, Murgia) na Itália (de Castellucci, Delbono) testemunha, entre muitos outros aspectos, o retorno duma forte dramaticidade, baseada no choque entre figuras e situações recortadas em cena de forma vigorosa, e cujos efeitos de continuidade narrativa podem associar elementos verbais e não-verbais, icónicos ou coreográficos, por exemplo.

Outro processo facilmente identificável no movimento que vai no sentido da abstração é a "dissociação da relação actor / personagem", na cena contemporânea que multiplica, há várias décadas, as modalidades através das quais a configuração dramática proposta pelo texto se decompõe e se recompõe no palco. Confusão das identidades, transferência do papel de um intérprete a outro, desmultiplicação dos intérpretes para um mesmo papel, variações de registos de presença que misturam actores reais e substitutos electrónicos, tratamento coral das vozes... o acontecimento teatral dissolve as modalidades habituais de atribuição da persona, da máscara individual, e o seu esperado enraizamento no corpo de um comediante. Mais uma vez, todavia, ter em consideração este fenómeno não deve levar-nos a julgar toda a forma de reelaboração da relação entre a figura e o intérprete como um retrocesso

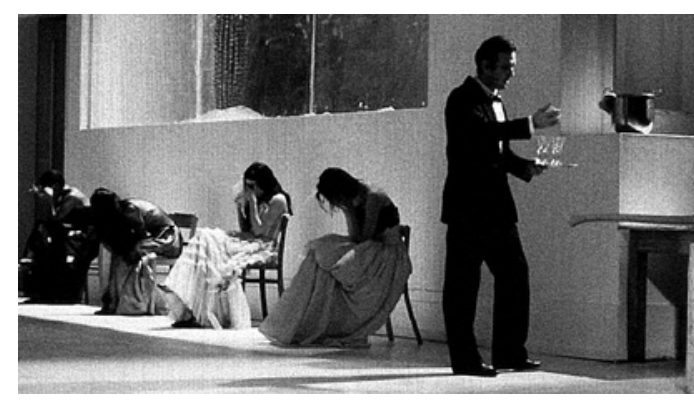

$<>$

Two Cigaretts in the Dark, de Pina Bausch, Brooklin Academy of Music, 1994, fot. $\odot$ Dan Rest / BAM. ou como um compromisso: a fase de deconstrução radical dos anos 1980 e 1990 - como, por exemplo, a de um Einar Schleef - já está ultrapassada, e vê-se com maior frequência hoje, numa mesma produção, um duplo movimento de conjunção e de disjunção da dupla actor / personagem a compor o espaço de uma teatralidade abertamente convencional, ao serviço da dramaturgia.

Uma terceira direcção do teatro pós-dramático consiste no que se poderia chamar a "suspensão do pacto ficcional", em que o acontecimento cénico deixa de se estruturar em ficções de personagens, de espaços ou de tempos, para se restringir a uma sucessão de acções fechadas sobre si próprias, e cujo carácter de simulação tende a desaparecer. Estas formas performativas, como são geralmente referidas hoje em dia, põem de novo em causa as codificações mais firmemente estabelecidas da representação teatral, deslocando as fronteiras do real e da sua mimese para reencontrar, mesmo que fugazmente, alguns dos modos operativos do ritual. Contudo, os happeningse as performances, na segunda metade do século XX, foram muito mais longe neste sentido: basta comparar, por exemplo, as acções de um Rodrigo Garcia às de um Hermann Nitsch, duma Angelica Lidell às de uma Gina Pane ou de um Chris Burden. Também a evolução que hoje atravessa o campo da criação teatral marca um processo de recuperação das explorações efectuadas nas esferas artísticas experimentais dos anos 1950-1970, no sentido também da eliminação das fronteiras entre os respectivos territórios do teatro, da dança, da performance e da instalação, mais do que uma mudança total e irreversivel das práticas cénicas. Neste ponto, como nos anteriores, é importante não reduzir a história da cena teatral à das zonas de experimentação mais radicais.
Trans-fixed, de Chris Burden, Venice, California, 1974 (Chris Burden), fot. Charles Hill, - Chris Burden. 
Estes três aspectos - dimensão narrativa, dupla actor I personagem, pacto ficcional - são indiscutivelmente o objecto, há várias décadas, de um processo de desconstrução tão completo que parece pôr de novo em questão a própria definição de teatro, porque leva a substituir a mimese duma acção dramática pela realização, por parte dos performers, de actos não simulados, sem relação perceptivel. Esta redução das artes do espectáculo aos seus constituintes minimais - corpos, gestos, um palco à frente dos espectadores - constitui o equivalente à que realizaram, nos anos 1910 e 1920, os inventores da pintura não figurativa, levando às suas mais extremas consequências o célebre axioma de Maurice Denis: "Lembrar-se que um quadro - antes de ser um cavalo de batalha, uma mulher nua ou uma historieta qualquer - é essencialmente uma superfície plana coberta de cores ligadas numa determinada ordem" (Denis 1920: 1). Nestes dois casos, uma arte explora as possibilidades expressivas que podem nascer unicamente do agenciamento interno dos seus elementos constitutivos, aquém de qualquer forma de representação.

Mas como se sabe, as obras de Kandinsky, Malevitch, Mondrian ou Kupka não constituíram um ponto sem retorno na história da pintura, fazendo oscilar toda esta arte no reino da abstração: antes pelo contrário, ela continuou a renovar-se através da exploração de múltiplas vozes - figurativas, parcialmente figurativas, não figurativas -, que tomaram todas em conta, para o prolongar, para se demarcarem ou para o reexaminar, o trabalho de desconstrução realizado nas primeiras décadas do século XX. Há portanto fortes probabilidades que, de maneira análoga, o desenvolvimento das poéticas cénicas do século XXI continue a explorar os procedimentos de dissociação típicas do teatro pós-dramático dos anos 1970-1990, mas recuperando algumas das questões maiores ligadas à narração, à figuração e à representação, sem as quais o público tenderá a diminuir cada vez mais.

\section{Referências bibliográficas}

BIDENT, Christophe (2009), "Et le théâtre devint postdramatique: histoire d'une illusion", Théâtre/Public, n. ${ }^{\circ}$ 194, Gennevilliers, septembre. BOURDIEU, Pierre (1992), Les règles de l'art: Genèse et structure du champ littéraire, Paris, Le Seuil.

DENIS. Maurice (1920), "Définition du néo-traditionnisme", Théories 18901910, Paris, L. Rouart et J. Watelin.

DIDI-HUBERMAN, Georges (1992), Ce que nous voyons, ce qui nous regarde, Paris, Éditions de Minuit.

FRANTZ, Pierre (2005), "Le théâtre est-il un art de l'image?", Critique, n. 699-700, Paris, Éditions de Minuit, août.

FUKUYAMA, Francis (1992), La fin de l'histoire et le dernier homme, Paris, Flammarion.

GOMBRICH, Ernst H. (1986), "Méditations sur un cheval de bois ou les origines de la forme artistique", Méditations sur un cheval de bois et autres essais sur la théorie de l'art, Mâcon, Editions W.

GREENBERG, Clement (1988), "Abstraction, figuration et ainsi de suite", Paris, Art et culture, Macula.

LEHMANN, Hans-Thies (1999), Das Postdramatisches Theater, Verlag der Autoren, Francfort/Main [trad. fr. Théâtre postdramatique, Paris, L'Arche, 2002].

MONTFORT, Anne (2009), "Après le postdramatique: narration et fiction entre écriture de plateau et théâtre néo-dramatique", Trajectoires, n. 3 [http://trajectoires.revues.org/392].

PLASSARD, Didier (2002), "Du théâtre, et de l'abstraction", Théâtre et art plastiques, entre chiasmes et confluences, Valenciennes, Presses Universitaires de Valenciennes.

SARRAZAC, Jean-Pierre (2007), "La réinvention du drame (sous l'influence de la scène)", Études théâtrales, n. ${ }^{\circ}$ 38-39, Louvain-la-Neuve, Centre d'Études théâtrales.

STEGERMANN, Bernd (2008), "Nach der Postdramatik", Theater heute, n. 10 , Friedrich Verlag, Berlin, octobre [tb.: http://www.schaubuehne.de/theorie].

Tradução de Sebastiana Fadda 